\section{FIVE CASES OF INJURY TO THE EYE FROM CHIPS OF STEEL.}

BY GEORGE F. HELM, M.D., F.R.C.S. ENG.,

OPHTHALMIC SURGEON TO THE CORNWALL INFIRMARY.

CASE 1.-In the spring of 1894 I was consulted by a man aged forty-five years who gave the following history. He had been struck nine years previously with a piece of steel, which entered the right eye and destroyed all vision. The tension of the eye was normal and the pupil was occupied by what was presumably a cataract. He had never' had the slightest pain in this eye or the fellow till five days before I saw him, when on hammering an old gas-pipe a piece of rust flew into his left eye. No wound was made by this, but when he first came to me he had iritis and nothing elseneither corneitis nor conjunctivitis. The anterior chamber was perfectly clear. The iris did not act to light and was of a different colour from the iris of the right eye. He was placed under vigorous treatment for a week, when, as the eye made no progress towards recovery, $I$ advised the removal of the blind and injured eye. On examining this eyeball after enucleation I found embedded in the centre of the vitreous chamber a piece of steel seven-sixteenths of an inch long and one-sixteenth of an inch broad. It had a firm fibrous capsule in which it lay. In a week's time the sympathising eye was apparently quite well and has remained so ever since.

CASE 2.- I was asked to examine an old man recently for the purpose of finding out whether he should undergo a cataract extraction. I first examined him by the aid of a lamp, and looking at his left eye I observed, "Why, you have a fly in your eye." "No, sir, that is a piece of steel." I inquired how long it had been there and he replied, "Twenty-five years." And, sure enough, there was a piece of steel sticking into his eyeball just over the ciliary region. I felt it with the probe and became convinced of the truth of his statement, and I need hardly say that I did not advise that any operation of extraction should be done either to the injured eye or to the uninjured, which had also become cataractous, as I supposed, from sympathetic ophthalmia. Moreover, there was a very bad perception of light in either eye.

CASE 3.-On Nor. 30th, 1895, a man aged sixty-two years came to the Truro Infirmary complaining of his vision. The right eye had been wounded by the point of a knife forty years previously; a portion of steel having broken off remained in the organ. He went to a medical man, who said he had removed the object, but the patient never saw the piece, from which I concluded that it had been pushed in instead of being withdrawn. Examining him ophthalmoscopically under atropine I saw the foreign body in the centre of the pupil, but behind it. The lens was perfectly clear and the foreign body appeared to be embedded in the front of the vitreous. It did not change its position with movements of the eye, but it effectually obstructed all central vision. He had hypermetropia of the other eye, which I rectified with spectacles, and advised him to carry the foreign body to his grave with him. At any rate, I refused to be a party to its removal, although $I$ did suggest that he should allow me to clear up all uncertainties by submitting to enucleation. This he wisely declined.

CASE 4.-A young man came to me in August last, being sent by Dr. Davy of Penzance, and was said to have a piece of steel in his right eye. It was plainly visible as a bright sparkling chip lying on the surface of the iris midway between the pupillary margin and the periphery in its lower segment. After instilling eserine I took him to the Truro Infirmary, where by means of the magnet I succeeded in withdrawing the foreign body through a small hole which I made in the cornea, enlarging the wound through which the piece had entered, making it just large enough to admit the point of the magnet. No aqueous escaped, so its withdrawal was accomplished without any difficulty, and the eye in a few days was perfectly normal in every respect, though when I operated, twenty-four hours after receipt of injury, mischief was commencing in the iris as shown by circum.corneal injection and slight discolouration of the iris.
CASE 5.-Another patient came about the same time as the preceding, having been hit by a piece of steel in the left eye, where it remained. His age was about fifty-five. It was perfectly visible, being about one-eighth of an inch long, and was sticking in the sclerotic about a quarter of an inch below the circumference of the cornea just over the ciliary region. I did not feel it with a probe, for not having any instrument at hand by which I could draw it out I feared that I might be the means of pushing it into the interior of the globe; and it seemed to be underneath the conjunctival opening it had made, so that there was nothing to take bold of. I took him to Truro Infirmary, where the magnet could be used and where all preparations hat been made, and when I opened the eyelids to commence operation the piece of metal was no longer visible. I endeavoured to find it with the point of the magnet, of course not placing it in the interior of the globe, and not finding it I desisted from any further attempt at its removal. In the course of a few weeks all damage to the eye had disappeared, but one day on examining it under homatropine I saw two oblong opacities apparently on the surface of the lens and corresponding in position to the direction which the foreign body had apparently taken. I have since examined this man and I cannot find any trace of injury to the interior of the eye. Of course he has the scar in the conjunctiva and sclerotic.

Truro.

\section{CASE OF TETANUS.}

BY ERNEST ST. CLAIR HENRIQUES,

STUDENT OF MEDICINE, ABERDEEN TNIVERSITY; FORMERLY MEDICAZ MISSIONARY OF 'THE UNIVERSITIES' MISSION TO CENTRAL AFRICA, BONDI.

[Introduced by Professor ALEX. OGSTON.]

Is the month of July, 1894, a little girl aged twelve years was brought by her mother to Mr. Herbert Ley, the medical officer in charge of the Magila Station of the Universities Mission to Central Africa, German East Africa. She complained of pain in the throat, and when told to open her mouth for examination refused. The medical officer thought that it was obstinacy on the part of the child and came to the conclusion that she was shamming, the throat seeming normal. He, therefore, prescribed a dose of salts. (I may mention that the little patient had to walk nearly a quarter of a mile to and from her own house, and did so quite unaided.) She would not take the draught prescribed by Mr. Ley, and eren when force was applied refused to open her mouth. Two days after this Mr. Ley was asked to visit the girl and found her exhibiting all the symptoms of tetanus. There were $a$ board-like feeling about the recti, stiffness of the muscles of the neck, and frequent spasms accompanied by sardonic grins. The following history was obtained. The patient had been quarrelling with a companion, and the pair were abont to come to blows when the guardian of girl No. 2 came out of her house, sided with her, and struck the patient with her open palm on the back of the neck. No pain was felt at the time and the child played about as usual for two fuls days. At the end of this period the pain and stiffen. ing of the throat appeared. The family history was as follows. Her father died from chronic nephritis, elephantiasis, and tuberculous disease of the lungs. Her mother and brother were quite healthy. It is the custom for African children to have their heads shaven, and Mr. Ley and myself thought that a wound might bave been caused by the knife, razor, or bit of broken glass used for this purpose. Every part of the body was carefully examined, but no scratch or wound could be discovered. A day after we saw her she died. Now arose a very interesting medico-legal point. Did the child die from the blow? The case was tried before the priest in charge of Magila, a native priest, and another African. The charge brought against the woman was witchcraft. Mr. Ley gave his evidence, which was that the girl died from tetanus and that a blow had been given. The woman received the benefit of the doubt and was not taken before the German anthorities, but had to pay a fine of eighty rupees as compensation.

Aberdeen. 